\title{
Temperature impact on dusty and cleaned photovoltaic module exposed in sub-Saharan outdoor conditions
}

\author{
N'detigma Kata $^{1,}$, Y. Moussa Soro ${ }^{2}$, Djicknoum Diouf ${ }^{1}$, Arouna Darga ${ }^{3}$, and A. Seidou Maiga ${ }^{1}$ \\ ${ }^{1}$ LEITER, Laboratoire Electronique, Informatique, Télécommunication et Energies Renouvelables Université Gaston Berger, \\ Saint-Louis, Senegal \\ 2 LESEE-2iE, Laboratoire Energie Solaire et Economie d'Energie, Institut International d'Ingénierie de l'Eau et de \\ l'Environnement, 01 BP 594 Ouagadougou 01, Burkina Faso \\ ${ }^{3}$ GeePs-CentraleSupelec, Laboratoire de Génie Electrique et Electronique de Paris, Universités de Sorbonne, UPMC Univ \\ Paris06, UMR 8507, 91190 Gif sur Yvette, France
}

Received: 6 April 2018 / Received in final form: 26 June 2018 / Accepted: 29 June 2018

\begin{abstract}
In this work, impacts of temperature and dust cleaning on photovoltaic module performance operating in sub-Saharan's climate are investigated. Two single junction technologies, monocrystalline and polycrystalline silicon, and one micromorph (amorphous/micrystalline) thin film silicon tandem technology are considered. We have recorded at the same time under real operating conditions, the module temperature and the current versus voltage characteristics of each module, and the local solar irradiation. All the measurements were performed with the outdoor monitoring and test facility located at Ouagadougou in Burkina Faso. The results show the drop of generated power of dusty modules for the same irradiation level. Between April and June (where temperatures are higher) a significant drop of output power is observed, despite a daily cleaning. Furthermore, performance losses are observed for all technologies compared to that under standard test conditions. However, the micromorph silicon tandem technology with low temperature sensitivity present the less losses in performance compared to the monocrystalline and the polycrystalline single junction modules, even if the modules are not cleaned.
\end{abstract}

Keywords: open circuit voltage / temperature coefficient / real operating conditions / dust / performance ratio

\section{Introduction}

Electrification rate in sub-Saharan Africa is around $35 \%$ in 2016 according to the International Energy Agency [1]. To compensate shortcoming of electrification in this region, governments have embarked on energy mix policies by promoting renewable energies. These last two years, we are witnessing the promotion of solar power plants in West African countries. This part of sub-Saharan region is characterized by the harsh climatic factors such as temperature, dust, humidity, wind, etc.

Some studies have been done under outdoor conditions in order to evaluate performance of the photovoltaic modules. In an early work, David A. Quansah et al. [2] performed measurements with silicon module on rooftop of building at the Kwame Nkrumah University Science and Technology. They showed that a polycrystalline module is the most performing one followed respectively by amor-

\footnotetext{
* e-mail: kata.ndetigma@ugb.edu.sn
}

phous module, Heterojunction Incorporating thin [2] film module and monocrystalline module. Elsewhere, A. Tossa et al. [3] showed that a micromorph module is best performing, followed by a monocrystalline module and a polycrystalline module from the same manufacturer. The less performing is a polycrystalline module from another manufacturer.

The losses of performance are due to modules' intrinsic parameters and climatic factors (extrinsic parameters). The influences of these extrinsic parameters on PV module performance have been largely investigated [4-8]. However, few studies [9] have been conducted on this influence in the sub-Saharan region. Most of time thin film modules are not used in these studies. In this paper, we consider one module of the micromorph silicon tandem technology and two single junction (one monocrystalline and one polycrystalline) modules of the silicon wafer-based technology. We evaluated modules' open circuit voltage under outdoor conditions of either daily clean modules or dusty ones. Modules performance is also examined as a function of temperature. 


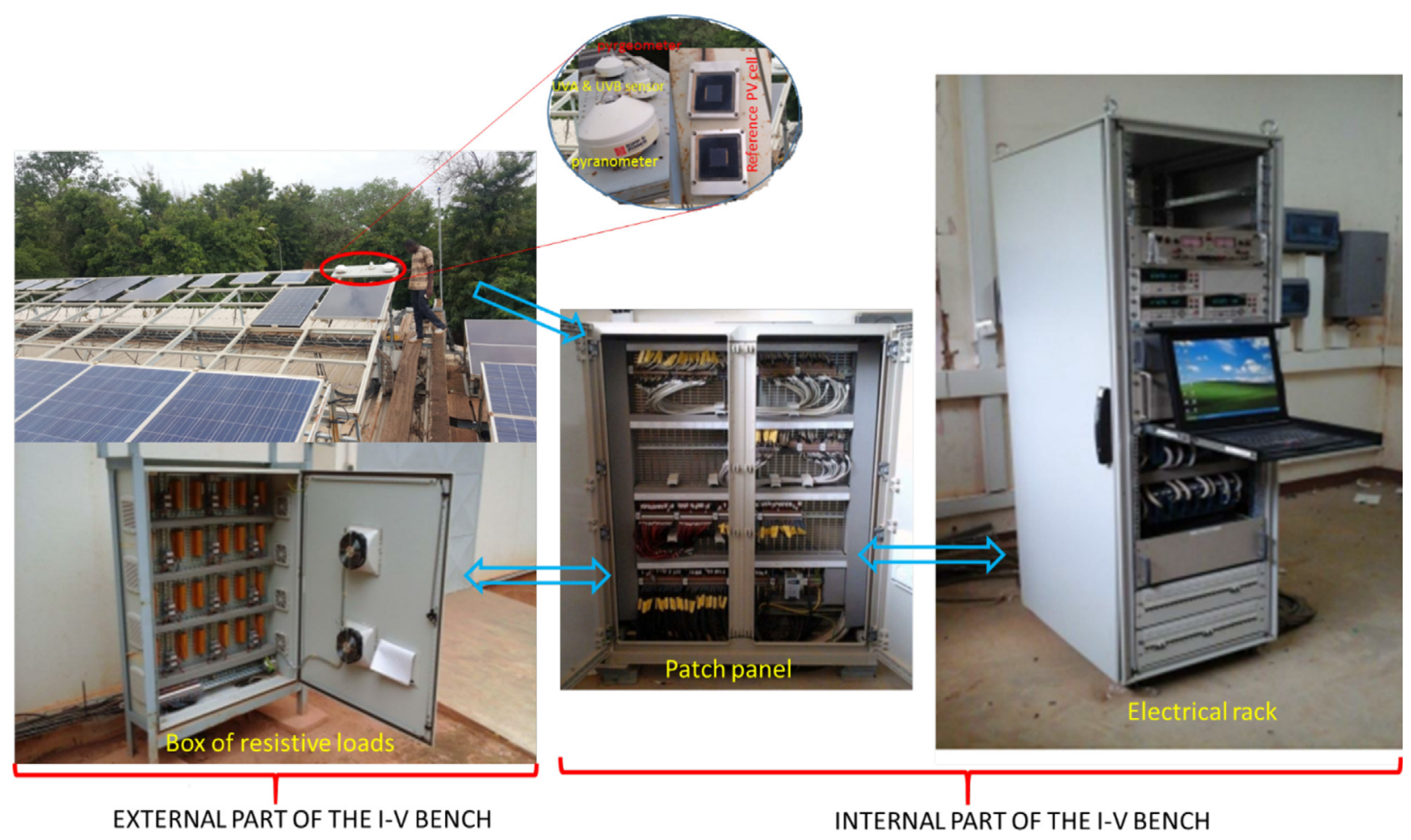

Fig. 1. A view of the $I-V$ bench at LESEE.

\section{Equipment details}

Current-voltage (I-V) characteristics measurements were performed at Laboratory of Solar Energy and Energy Saving (LESEE) of International Institute of Water and Environment Engineering (2iE) of Burkina Faso using outdoor monitoring test facility named "IV bench" and shown in Figure 1.

Four silicon based PV modules were studied:

- a single junction monocrystalline (mc-Si) module from manufacturer 1 labeled VSP50M-12V;

- a single junction polycrystalline ( $\mathrm{pc}-\mathrm{Si}$ ) module from the same manufacturer labeled VSP50P-12V;

- a single junction polycrystalline (pc-Si) module from manufacturer 2 labeled SW50 RMA/D;

- a micromorph module (tandem of amorphous and microcrystalline thin film cells) labeled NA-F128GK.

Table 1 shows data specification for these modules installed on the rooftop of the LESEE at Kamboinse (Ouagadougou-Burkina Faso). Measurements from midOctober 2014 to July 2015 divided in two periods (Fig. 2) were performed as follow:

- from August 1st, 2014 to January 13, 2015, modules were not cleaned during measurement;

- from January 14, 2015 to July 31, 2015, modules were cleaned daily.

The temperature and sun irradiation were measured at the same time as the module $\mathrm{I}-\mathrm{V}$ characteristic. Three multimeters are used to measure simultaneously module voltage and module current whereas a pyranometer was used to measure the sun irradiation. The module temperature was measured by a PT100 temperature sensor stuck with thin aluminium tape at the back of the module. The two measurements of $\mathrm{I}-\mathrm{V}$ data were separated by a 5 min interval and the time required to complete the I-V curve was less than $2 \mathrm{~s}$. Then, the solar irradiation can be considered constant for each $\mathrm{I}-\mathrm{V}$ measurement. The range of $-0.5 \mathrm{~V}$ to $105 \%$ of the open circuit voltage (Voc) was applied to the module. All $\mathrm{I}-\mathrm{V}$ data stemming from measurements are stored in CSV Excel format on PC.

\section{Results and discussion}

\subsection{Effect of dust on maximum power output}

Dust and soiling remain problems for solar plant performance in dusty regions of the world, especially in the subSaharan region which ironically have one of the best solar irradiation. One approach in studying dust impact is to investigate its effect on the transmittance of PV transparent cover glass. Module performance degradation is reported with dusty module [10]. The accumulation of dust on the surface of the PV modules, reduces the cover glass transmittance and hence, decreases the amount of solar irradiation reaching solar cells. Said et al. [11] studied the effect of dust fouling on the transmittance of $\mathrm{PV}$ module cover glass and showed a reduction of $20 \%$ in glass transmittance of modules exposed for 45 days. Sarver et al. [12] made a review which examines and summarizes the research, development and challenges relating to the dust 
Table 1. Specifications of photovoltaic modules used during the test (STC).

\begin{tabular}{|c|c|c|c|c|}
\hline \multirow[t]{2}{*}{ Modules specifications } & \multicolumn{4}{|c|}{ PV modules } \\
\hline & $\begin{array}{l}\text { m-Si } \\
\text { (VSP50M-12V) }\end{array}$ & $\begin{array}{l}\text { p-Si } \\
\text { (VSP50P-12V) }\end{array}$ & $\begin{array}{l}\text { p-Si } \\
\text { (SW50 RMA/D) }\end{array}$ & $\begin{array}{l}\text { aSi:H/ } / \mu \mathrm{c}-\mathrm{Si}: \mathrm{H} \\
\text { (NA-F128GK) }\end{array}$ \\
\hline Short current Isc (A) & 3.16 & 3.09 & 2.95 & 3.45 \\
\hline Open circuit voltage Voc (V) & 22.2 & 22.2 & 22.1 & 59.8 \\
\hline Maximum power current Imp (A) & 2.78 & 2.85 & 2.75 & 2.82 \\
\hline Maximum power voltage Vmp (V) & 18 & 18 & 18.2 & 45.4 \\
\hline Maximum power Pmp (W) & 50 & 50 & 50 & 128 \\
\hline Isc temperature coefficient $\left(\% /{ }^{\circ} \mathrm{C}\right)$ & 0.037 & 0.037 & 0.081 & 0.07 \\
\hline Voc temperature coefficient $\left(\% /{ }^{\circ} \mathrm{C}\right)$ & -0.34 & -0.34 & -0.37 & -0.3 \\
\hline Pmp temperature coefficient $\left(\% /{ }^{\circ} \mathrm{C}\right)$ & -0.48 & -0.48 & -0.45 & -0.24 \\
\hline Area $\left(\mathrm{m}^{2}\right)$ & 0.4104 & 0.6318 & 0.3482 & 1.4217 \\
\hline Number of cells & 36 & 36 & 36 & 180 \\
\hline Efficiency (\%) & 12.18 & 12.23 & 10.81 & 9 \\
\hline
\end{tabular}

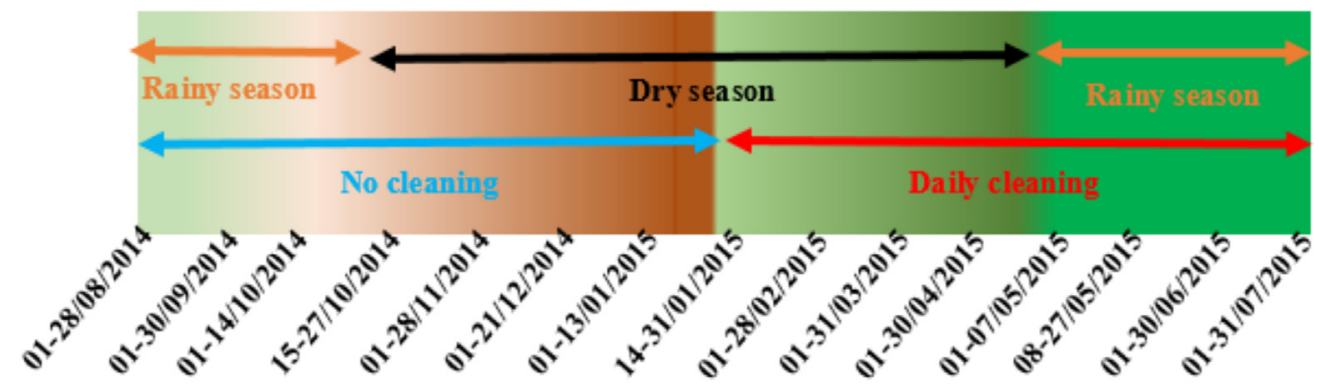

Fig. 2. Module cleaning planning.

issue for solar collectors. It was reported from those studies that glass transmittance is reduced and reduction depends on the dust density that lays on its surface, the tilt angle, the orientation on the dominant wind direction, the exposure period and the site climatic condition [13,14]. The effect of dust on the power output and currentvoltage characteristic of PV module depends not only on the factors that enhance transmittance, but also of dust composition and its particle distribution $[15,16]$. We considered for the study, irradiation intensity of $800 \mathrm{~W} /$ $\mathrm{m}^{2}$ or greater in order to examine dust impact on module operating in the warm climate of the sub-Saharan region. Figures 2 and 3 show the modules cleaning planning and the monthly average of maximum power output for irradiation of $801 \mathrm{~W} / \mathrm{m}^{2}$, respectively. The monthly average of maximum power output is obtained by equation (1):

$$
\text { Power, } P_{\max }=\frac{\sum_{i}^{m} P_{\max , i}}{m} .
$$

$m$ is the number of $\mathrm{I}-\mathrm{V}$ measurements performed in the month and $P_{\max , i}$ the maximum output power for $i$ th measurement.

Power delivered by all modules decreased continuously from August to mid-January due to dust accumulation. During that period modules were not cleaned. From the

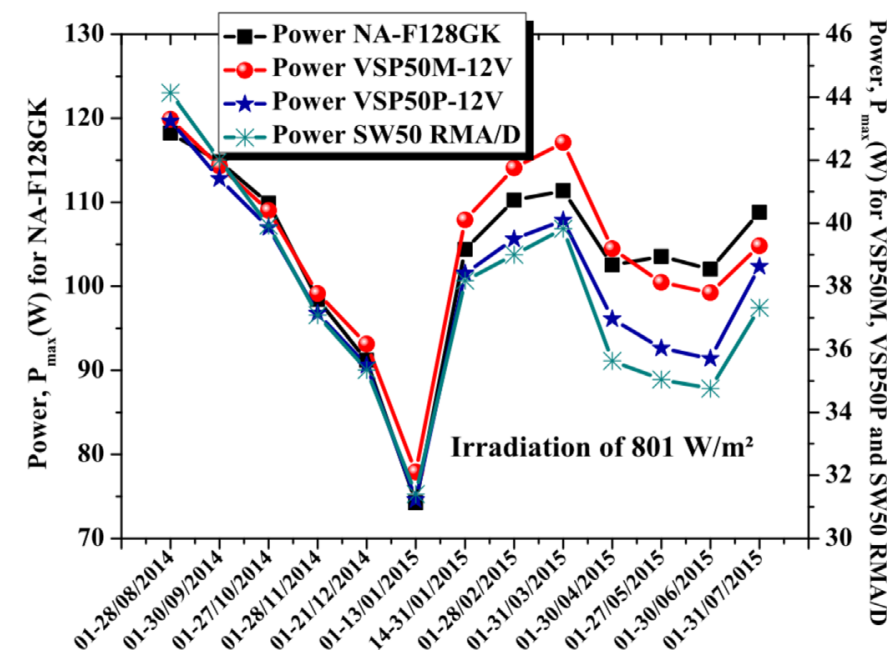

Fig. 3. Monthly average maximum power output.

second mid-January, the power output for all the modules increased because of the daily cleaning which started on January 14, 2015 (see on Fig. 3). From April to June, power output dropped to an almost constant value. This fall can be explained by the effect of temperature. Figure 4 shows the modules monthly average temperature calculate with 


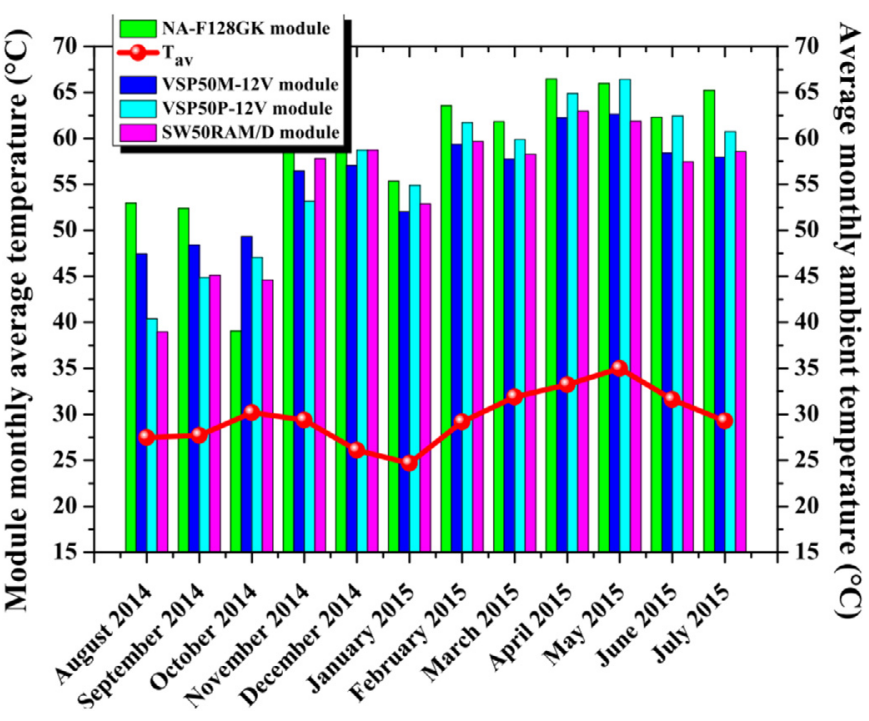

Fig. 4. Module and ambient average temperature.

equation (2).

$$
\text { module monthly average temperature }=\frac{\sum_{i}^{n} T_{m, i}}{n} .
$$

$T_{m, i}$, the module temperature during the $i$ th $\mathrm{I}-\mathrm{V}$ measurement, $n$ the number of $\mathrm{I}-\mathrm{V}$ measurements in the month.

The modules monthly average temperature are slightly high around the months of March and April. This period coincides with the transition between the dry season and the rainy season, marked by a heat wave coupled with no aeration in Burkina Faso (see the ambient average temperature $\left(T_{a v}\right)$ of Ouagadougou city [9] on Fig. 4). Thus, the heat exchange between the modules and the outside is slowed down and that induces module performance loos. On Figure 4, it is also observed that the average monthly temperature of the module NA-F128GK is always the highest except in October. This is probably due to a technical problem that occurred on the temperature sensor of this module during measurements made in October.

\subsection{Influence of temperature on Voc}

The open circuit voltage (Voc) of a solar cell characterizes the state where total rate of photogeneration equals that of recombination so that total current through the circuit is null. The temperature sensitivity of open circuit voltage is of particular importance since it accounts for $80-90 \%$ of the overall temperature sensitivity for reasonably good solar cells [17]. Green have delivered the general expression for temperature sensitivity of the open circuit voltage which is always valid but required the knowledge of the recombination mechanism in the cell for simplification. Dupré et al. deduced from this expression temperature sensitivity of Voc for radiative recombination in a good solar cell [18] as:

$$
\beta=-\frac{\frac{E_{g 0}}{q}-V_{o c}+\gamma \frac{k T}{q}}{T}
$$

$$
\text { where } \begin{aligned}
\gamma= & 1-\frac{d \ln E R E_{o c}}{d \ln T} \\
& +\left(2 \frac{d \ln E_{g}}{d \ln T}-\frac{d \ln J_{s c, 1 s u n}}{d \ln T}\right) .
\end{aligned}
$$

$E R E_{o c}$ is External Radiative Efficiency at open circuit, $E_{g 0}$ is the semiconductor bandgap relevant to the recombination process of interest, extrapolated linearly from the temperature of interest to $0 \mathrm{~K}, T$ is the module temperature, $q$ the elementary charge and $k\left(1.381^{*} 10^{-23} \mathrm{~J} / \mathrm{K}\right)$ the Boltzmann constant. Equation (3) predicts a temperature coefficient of the open circuit voltage approximately constant over the range of temperature typical of solar cell operation [18].

$E R E_{o c}$ is deduced from reference [19] as follow:

$$
E R E_{o c}=\frac{\frac{2 \pi q}{h^{3} C^{2}} \exp \left(\frac{q V_{o c}}{k T}\right) \int \frac{\overline{E Q E}_{a b s} E^{2} d E}{\exp (E / k T)-1}}{J_{s c}}
$$

where $E Q E$ is the External Quantum Efficiency of solar cells for near-perpendicular incident light, $\overline{E Q E}$ the appropriately weighted value over all angles of incident light (not different from $E Q E$ for high quality cells), $c$ is the speed of light in vacuum and $h$ the Planck's constant. In the numerator, the major contribution to integration comes from the long wavelength region of the spectral response, from the region where this response begins to fall rapidly to the low value near the absorption threshold, whereas the main contribution in the denominator comes from the region near the peak photon density in the AM1.5 solar spectrum [19]. Photon density is a function of incident spectrum, concentration, reflection and transmission. Making the rough approximations of neglecting the bandgap temperature dependences, it was shown elsewhere [18] that $\beta$ increased with $\gamma$.

From equation (3), the open circuit voltage can be deduced as:

$$
V_{o c}=\left(\beta+\frac{\gamma k}{q}\right) T_{c}+\frac{E_{g 0}}{q} .
$$

If the dark saturation current is dominated by recombination within the space charge region with an ideality factor close to two, the term $\gamma$ reads $5-2 \frac{d \ln J_{s c}}{d \ln T_{c}} \approx 5$ [18]. If the dark saturation current is dominated by bulk and surface recombination with an ideality factor close to unity, $\gamma$ becomes $3-\frac{d \ln J_{s c}}{d \ln T} \approx 3[18]$. In the same reference values range from 0 to 2 of $\gamma$ is observed proving that there are other configuration than the two described above. Whatever $\gamma$ value, the term $\frac{\gamma k}{q}$ i.e. $\left(8.617 \times 10^{-5} \times \gamma\right)$ is neglected [18] behind the open circuit voltage temperature coefficient $(\beta)$ of the fourth modules: $-0.179 \mathrm{~V} /{ }^{\circ} \mathrm{C}$, $-0.075 \mathrm{~V} /{ }^{\circ} \mathrm{C}, \quad-0.075 \mathrm{~V} /{ }^{\circ} \mathrm{C}, \quad-0.082 \mathrm{~V} /{ }^{\circ} \mathrm{C}$ at standard conditions for micromorph (NA-F128GK), polycrystalline (VSP50P-12V), monocrystalline (VSP50M-12V) and polycrystalline (SW50 RMA/D) respectively. Then the equation (6) becomes:

$$
V_{o c}=\beta T_{c}+\frac{E_{g 0}}{q}
$$



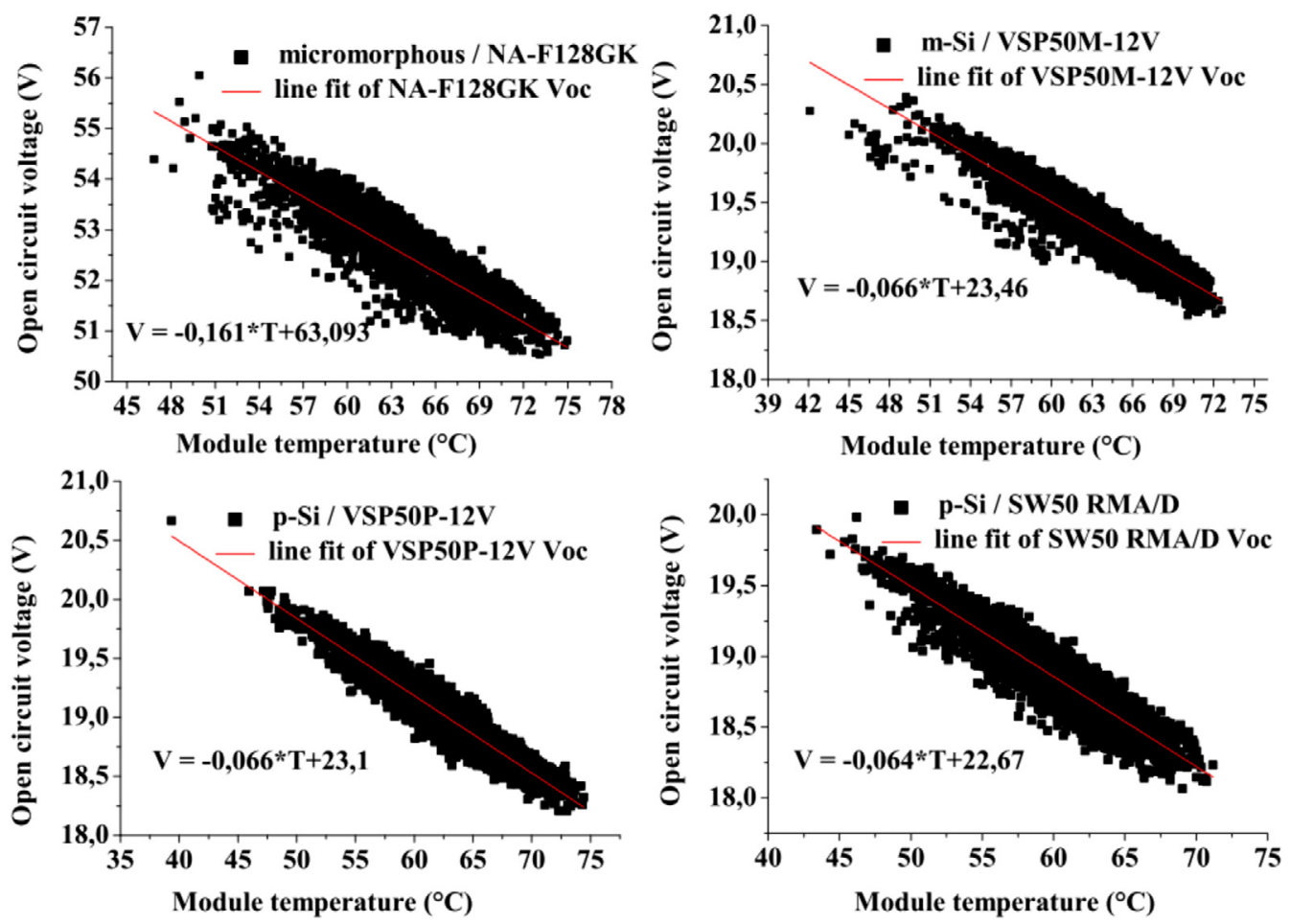

Fig. 5. Open circuit voltage temperature dependence for the cleaned module.

For experimental measurements, the open circuit voltage temperature dependence is examined considering dry season period (Fig. 2) in order to avoid the effect of rainfall on measurements. In Figures 5 and 6 , results for cleaned and non-cleaned periods of the modules are shown respectively. The open circuit voltage temperature dependence of different modules is given by linear fitting of Voc curve with the general expression in the form of equation (8):

$$
V_{o c}=\alpha T_{c}+\phi
$$

The temperature sensitivity of $\operatorname{Voc}(\beta)$ and $\frac{E_{g 0}}{q}$ depend on recombination mechanisms (radiative, Shockley Read Hall, Auger, surface, shunts) that take place in solar cell. In the case of radiative recombination mechanism in the solar cell, $E_{g 0}$ is equal to $1.2 \mathrm{eV}$ for monocrystalline silicon solar cell. Then, the $\frac{E_{g 0}}{q}$ value for the used monocrystalline module (VSP50M-12V, 36) should be approximately equal to $43.2 \mathrm{~V}$. This value is far and away different from the extrapolation value $(\phi)$ from experimental data of the same module. So, in addition to radiative recombination mechanism, there are other recombination that occurred in these solar cells.

The impact of cleaning on the $\operatorname{Voc}(0 \mathrm{~K})$ is observed for all modules. Table 2 shows Voc temperature coefficient calculated by using equation (9):

$$
\alpha\left[\% /{ }^{\circ} \mathrm{C}\right]=\frac{\alpha\left[V /{ }^{\circ} \mathrm{C}\right]}{V_{o c, S T C}[V]} .
$$

As seen in Table 2, the cleaned modules present higher Voc temperature coefficient than the dusty ones even if these temperature coefficients are smaller than those given at STC by manufacturers. This could be explained by the effect of the particularly high temperature during the cleaning period (Fig. 2). Figures 7 and 8 show the temperature sensitivity of the open circuit voltage of the cleaned modules for the less hot period (from the 14th of January to end of March) and for the hot period (from April to May) respectively. We note a relatively higher temperature coefficient of the Voc of the modules during the months with the high modules temperature.

In order to examine the impact of the climate factors above-mentioned on the performance of the different solar cell technologies, we use the comparison criteria described by the CEI 61724 standard [20]. Among them three are often used to compare different photovoltaic technologies according to their productivity, the available solar resource and the set of system losses. These are the reference efficiency, the specific energy efficiency and the performance ratio. Since the used modules electrical specifications are different, the performance ratio becomes the best parameter of comparison.

\subsection{Module performance}

The performance ratio is defined as:

$$
P R=\frac{\eta}{\eta_{S T C}}
$$



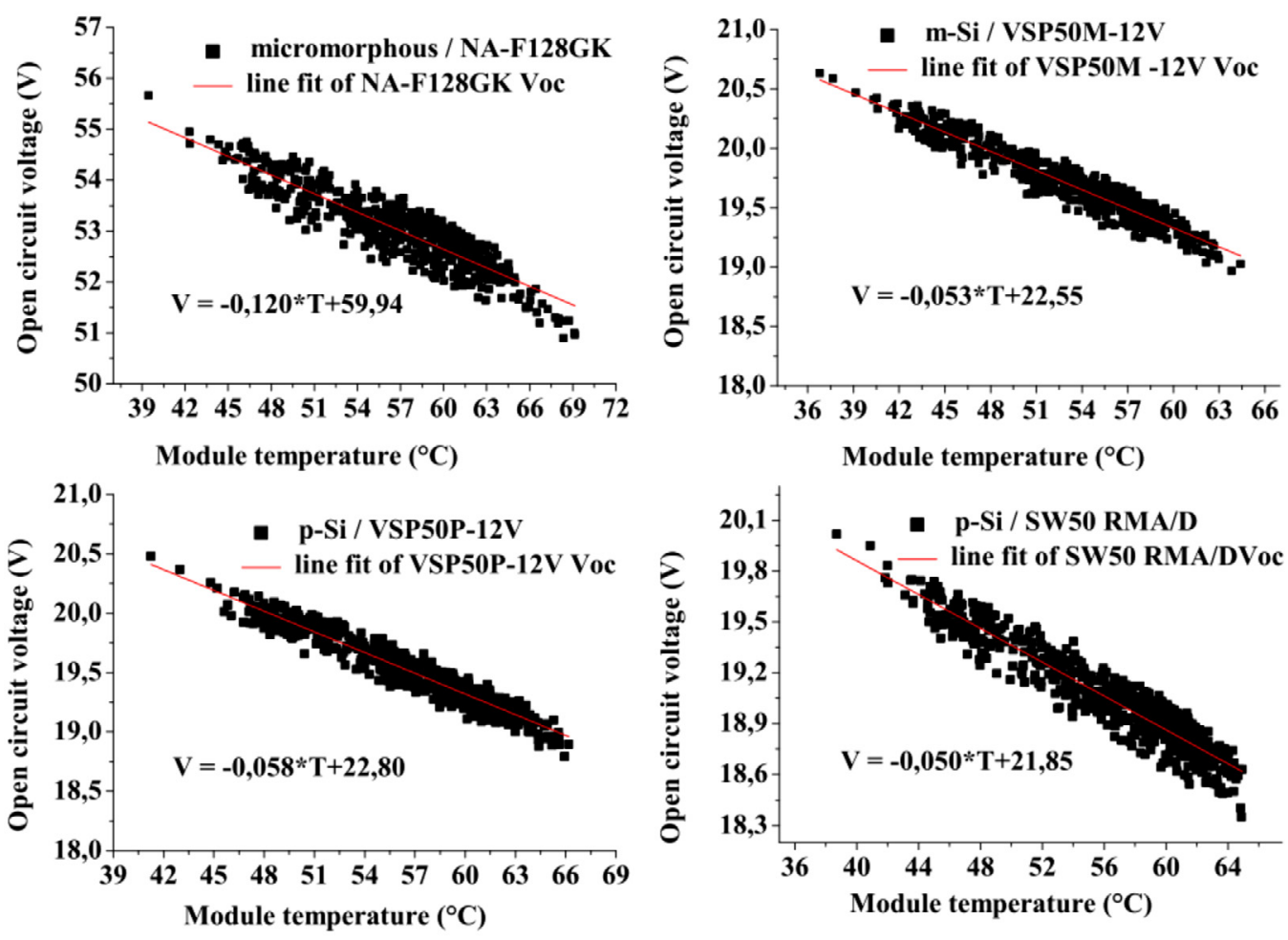

Fig. 6. Open circuit voltage temperature dependence for module without cleaning.

Table 2. Open circuit voltage temperature coefficient of modules.

\begin{tabular}{llllll}
\hline & & $\mathrm{m}-\mathrm{Si}$ & $\mathrm{p}-\mathrm{Si}$ & $\mathrm{p}-\mathrm{Si}$ & $\mathrm{aSi}$ H $/ \mu \mathrm{c}-\mathrm{Si}: \mathrm{H}$ \\
& & VSP50M-12V & VSP50P-12V & SW50 RMA/D & NA-F128GK \\
\hline Module in STC & $\begin{array}{l}\text { Voc temperature } \\
\text { coefficient }\left[\% /{ }^{\circ} \mathrm{C}\right]\end{array}$ & -0.34 & -0.34 & -0.37 & -0.3 \\
$\begin{array}{l}\text { Module with daily } \\
\text { cleaning }\end{array}$ & $\begin{array}{l}\text { Voc temperature } \\
\text { coefficient }\left[\% /{ }^{\circ} \mathrm{C}\right]\end{array}$ & -0.3 & -0.3 & -0.29 & -0.27 \\
$\begin{array}{l}\text { Module without } \\
\text { cleaning }\end{array}$ & $\begin{array}{l}\text { Voc temperature } \\
\text { Coefficient }\left[\% /{ }^{\circ} \mathrm{C}\right]\end{array}$ & $-0.59 \mathrm{e}-4$ & $4.06 \mathrm{e}-4$ & $5.21 \mathrm{e}-4$ & $1.64 \mathrm{e}-3$ \\
& Standard error & $6.81 \mathrm{e}-4$ & -0.26 & -0.23 & -0.2 \\
& & $6.5 \mathrm{e}-4$ & $6.73 \mathrm{e}-4$ & $2.3 \mathrm{e}-3$ \\
\hline
\end{tabular}

where, $\eta$ is the real efficiency of the module under a given condition and $\eta_{S T C}$, the module efficiency under STC.

These are given respectively by:

$$
\eta=\frac{P_{m p}}{S \times G}
$$

and

$$
\eta_{S T C}=\frac{P_{m p, S T C}}{S \times G_{S T C}}
$$

where $S$ is the module area, $P_{m p}$ the real maximum power, $P_{m p, S T C}$ the maximum power under STC, $G$ the solar irradiation and $G_{S T C}$ the solar irradiation under STC.
The combination of the three equations allowed to express the performance ratio as:

$$
P R=\frac{P_{m p}}{P_{m p, S T C} \times \tau}
$$

where,

$$
\tau={ }^{G} / G_{S T C} .
$$

The value of $G$ is obtained with a pyranometer whose measurements are influenced by the ambient temperature (factor not negligible in environment of study), the wind speed, etc. Thus, to avoid errors in estimating the value of $G, \tau$ is expressed as a function of the short-circuit current of 

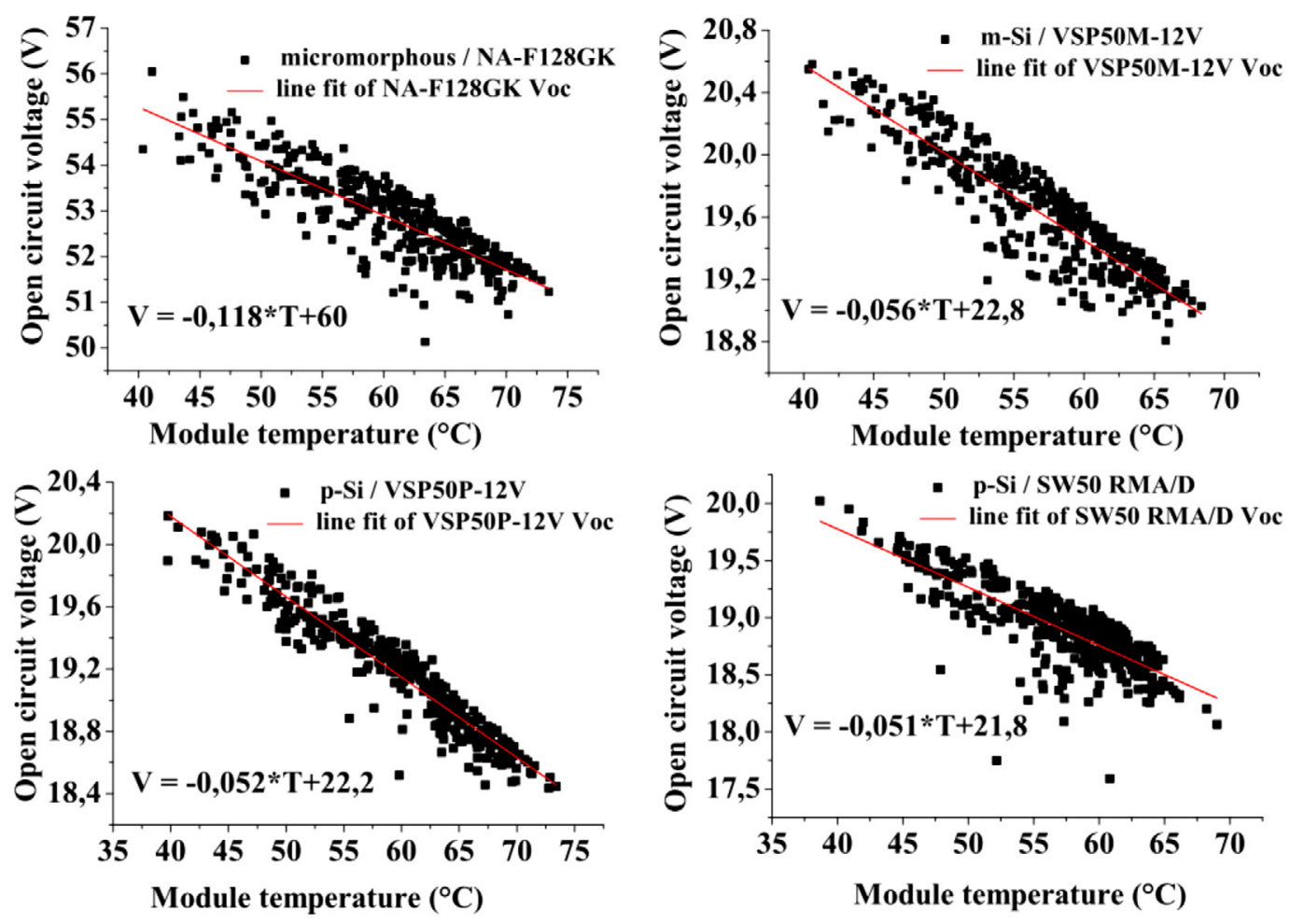

Fig. 7. The Voc temperature dependence for the cleaned module during the less hot periods.
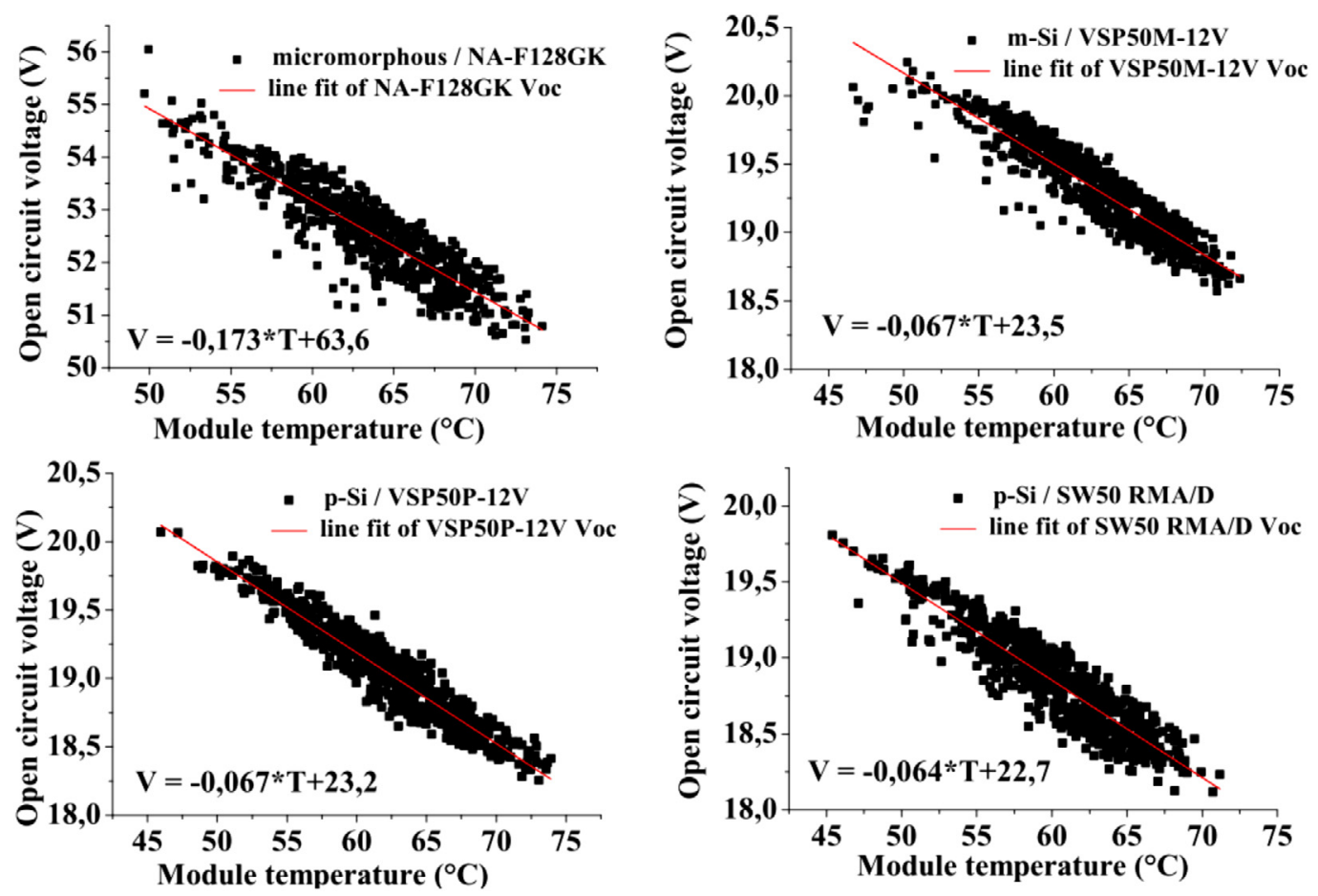

Fig. 8. The Voc temperature dependence for the cleaned module during the hot periods. 


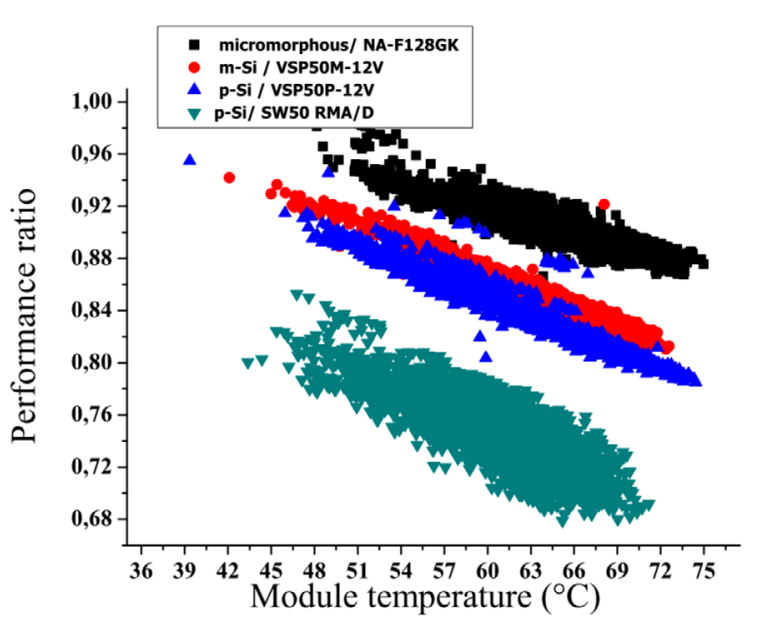

(a)

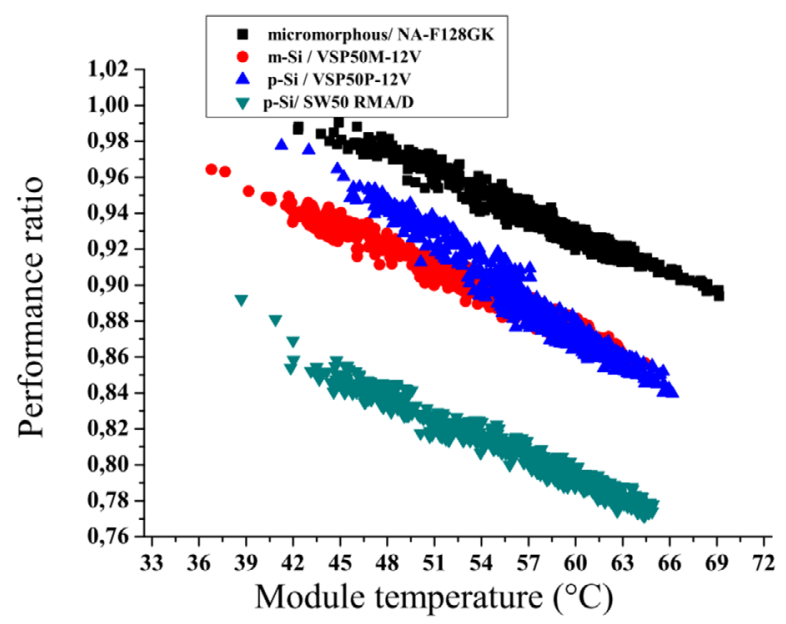

(b)

Fig. 9. Performance ratio of cleaned module (April to June) (a) and period without cleaning (b).
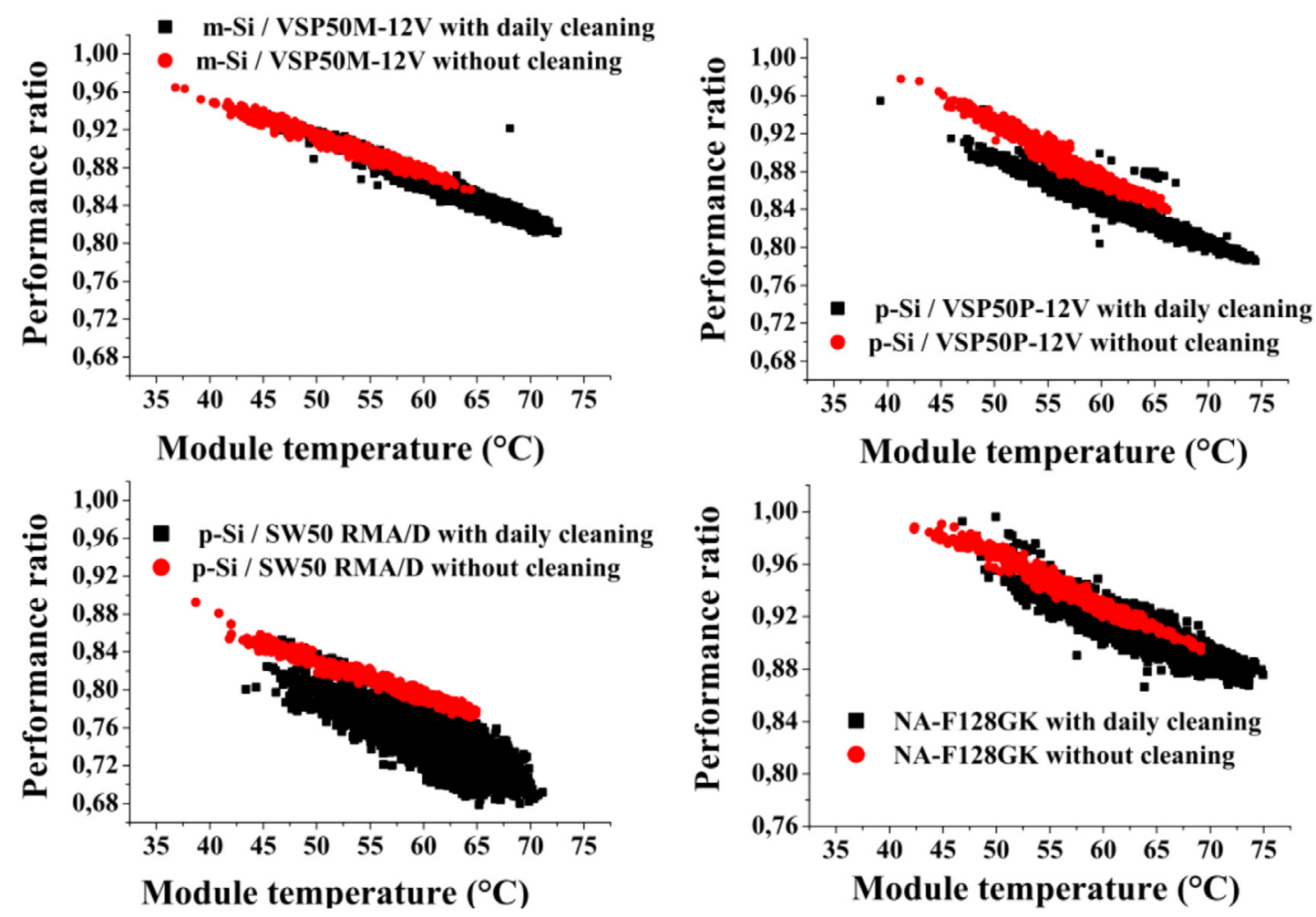

Fig. 10. Performance ratio comparison between clean module (April to June) and dusty module.

the module. The short-circuit current of a PV module can be considered equivalent to a photocurrent, proportional to the irradiation. It increases slightly with the temperature of the module and can be modeled by equation (15) [21]:

$$
I_{s c}=I_{s c, S T C} *\left[1-\theta\left(T_{c e l l}-25\right)\right] \frac{G}{G_{S T C}}
$$

where, $\theta={ }^{\alpha_{j s c}} / I_{s c . S T C}$. $\alpha_{j s c}$ is short-circuit current temperature coefficient $\left(\mathrm{A} /{ }^{\circ} \mathrm{C}\right.$ ). $\theta$ is equal to $3.7 \times 10^{-4} /{ }^{\circ} \mathrm{C}$ (for VSP50M- $12 \mathrm{~V}$ and VSP50P-12V modules), $8.1 \times 10^{-4} /{ }^{\circ} \mathrm{C}$ (for SW50RMA/D module) and $7^{*} 10^{-4} /{ }^{\circ} \mathrm{C}$ (for NA-F128GK module). So the term $\theta\left(T_{\text {cell }}-25\right)$ is neglected behind 1 .

Then,

$$
\tau=\frac{I_{s c}}{I_{s c, S T C}}
$$


Performance ratio results of different modules studied are shown in Figures 9a and 9b for time periods where the modules were cleaned or not, respectively.

As indicated in Figure 9 the performance ratio decreases with increasing temperature for all technologies in both (cleaning/ no cleaning) cases. Tandem structure module (micromorphous NA-F128GK) showed the best performance followed by monocrystalline and polycrystalline of the same manufacturer 1 . The polycrystalline of manufacturer 2 has the lowest performance however its Voc temperature coefficient is lower than that of the module of manufacturer 1. This behavior is explained by the high temperature dependence of its resistance [6]. Furthermore, monocrystalline of manufacturer 1 has a higher performance than polycrystalline of the same manufacturer when modules are cleaned. This is no longer the case when modules are dusty. In the case of Figure $9 \mathrm{~b}$, the polycrystalline module has higher performance than the monocrystalline one for temperatures lower than $57^{\circ} \mathrm{C}$, despite its high Voc temperature coefficient. Based on the principle that the dust deposit is identical on both modules, this monocrystalline module is more affected by dust than the polycrystalline one. As the polycrystalline module has a higher temperature coefficient, its loss of performance became more important for the higher module temperature $\left(T>57^{\circ} \mathrm{C}\right)$.

Figure 10 shows the performance of different modules either cleaned (period of April to June) or not. Though the modules are cleaned, their performance is lower than that of non-cleaned modules. This observation is due to a relatively higher module temperature during the cleaning period and the higher open circuit voltage temperature coefficient compared with dusty module as explained in Section 3.2. Owing to this observation, it is important to note that even if dust is a significant influential outdoor factor for modules' performance in sub-Saharan region, the impact of temperature is to be taken into consideration rigorously.

\section{Conclusion}

The impact of temperature and dust cleaning on module operating in the sub-Saharan climate has been studied and discussed. It has been shown that: module power output fall down with dust laying and higher operating temperature mainly between April and June for cleaned modules; performance losses for all technologies due to climatic factors cited above; a-Si/micromorhpous silicon module based on the tandem technology demonstrated low temperature coefficient which make it more suitable than monocristalline and polycrystalline modules in subSaharan operating conditions; further investigations are need in order to find among all the commercial photovoltaic module technologies, the least sensitive to temperature and so well adapted to the real sub-Saharan operating conditions.
All the acknowledgements to the support of the African Centre of Excellency in Mathematics, Informatics and TIC (CEA-MITIC) and Laboratory of Solar Energy and Energy Saving (LESEE) of International Institute of Water and Environment Engineering $(2 \mathrm{iE})$.

\section{Author contribution statement}

This paper is result of a research internship conducted at LESEE laboratory by N. Kata, a PhD. Student under the direction of Y.M. Soro, a member of LESEE. The data analysis is done by N. Kata under the supervision of D. Diouf and A. Darga. Professor A. Seïdou Maïga is the director of the thesis and oversee the entire study of the paper.

\section{References}

1. International Energy Agency, World energy outlook 2016 (2016)

2. D.A. Quansah, M.S. Adaramola, G.K. Appiah, Int. J. Hydrogen Energy 42, 1 (2016)

3. A.K. Tossa, Y.M. Soro, L. Thiaw, Energy 1103, 261 (2016)

4. J.K. Kaldellis, M. Kapsali, Energy 36, 5154 (2011)

5. S.A.M. Said, G. Hassan, H.M. Walwil, N. Al-Aqeeli, Renew. Sustain. Energy Rev. 82, 743 (2018)

6. M. Mani, R. Pallai, Renew. Sustain. Energy Rev. 14, 3124 (2010)

7. M.J. Adinoyi, S.A.M. Said, Renew. Energy 60, 633 (2013)

8. E. Skoplaki, J.A. Palyvos, Sol. Energy 183, 614 (2009)

9. infoclimat.fr [on ligne] (2001), Available: https://www. infoclimat.fr/climatologie [Accessed 11 september 2017]

10. A. Ndiaye, C.M.F. Kébé, P.A. Ndiaye, Acad. J. 8, 1166 (2013)

11. S.A.M. Said, H.M. Walwil, Sol. Energy 107, 328 (2014)

12. T. Sarver, A. Al-Qaraghuli, L.L. Kazmerski, Renew. Sustain. Energy Rev. 22, 698 (2013)

13. H.K. Elminir, A.E. Ghitas, R.H. Hamid, F. El-Hussainy, M.M. Beheary, K.M. Abdel-Moneim, J. Energy Convers. Manage. 147, 192 (2006)

14. AA. Hegazy, Renew. Energy 122, 525 (2001)

15. M.S. El-Shobokshy, F.M. Hussein, Renew. Energy 16, 585 (1993)

16. R.E. Cabanillas, H. Munguia, Renew. Sustain. Energy 3, 043114 (2011)

17. M.A. Green, Prog. Photovolt. Res. Appl. 11, 333 (2003)

18. O. Dupré, R. Vaillon, Sol. Energy Mater. Sol. Cells 140, 92 (2015)

19. M.A. Green, Prog. Photovolt. Res. Appl. 20, 472 (2012)

20. IS/IEC 61724, Photovoltaic System Performance Monitoring - Guidelines for Measurement, Data exchange and Analysis - is.iec.61724.1998.pdf [Online] (1998), Available: https:// law.resource.org/pub/in/bis/S05/is.iec.61724.1998.pdf [Accessed: 08 June 2018]

21. E. Koutroulis, D. Kolokotsa, A. Potirakis, K. Kalaitzakis, Sol. Energy 80, $1072(2006)$

Cite this article as: N'detigma Kata, Y. Moussa Soro, Djicknoum Diouf, Arouna Darga, A. Seidou Maiga, Temperature impact on dusty and cleaned photovoltaic module exposed in sub-Saharan outdoor conditions, EPJ Photovoltaics 9, 8 (2018) 